\title{
Dominant Lactic Acid Bacteria and Their Antimicrobial Profile from Three Fermented Milk Products from Northern Namibia
}

\author{
L. N. Heita, A. Cheikhyoussef \\ Science, Technology and Innovation Division, Multidisciplinary Research Centre, University of Namibia, Private \\ Bag 13301, 340 Mandume Ndemufayo Avenue, Pionierspark, Windhoek, Namibia \\ Email: acheikhyoussef@unam.na, acheikhyoussef@gmail.com
}

Received October 2014

\section{Abstract}

The present study focused on the isolation, identification and antimicrobial profile of the dominant lactic acid bacteria from three traditional fermented milk products namely: Omashikwa, Mabisi and Mashini Ghamushikwa from the north-central and north-eastern parts of Namibia. The microbiological and antimicrobial activities of these products fluctuate from one region to another depending on the local indigenous microflora. Omashikwa and Mashini Ghamushikwa fermentation processes involves the addition of Boscia albitrunca root (Omunkuzi) and butter churning. The root contributes to the flavor of the product, increasing the milk fermentation rate and churning. Mabisi is produced by letting the milk to ferment naturally until the water is separated from the whey. The water is then decanted, and the whey is shaken until it is smooth without removal of fat. A total of 180 isolates of Lactic acid bacteria (LAB) were obtained and identified based on their phenotypical characterization. Cell free supernatants (CFS) of the 180 LAB isolates were evaluated for antimicrobial activities against selected food borne pathogens; Escherichia coli ATCC 25,922, Staphylococcus aureus ATCC 25,923, Bacillus cereus ATTC 10,876, Candida famata and Geotrichum klebahnii using the well diffusion assay. Twenty LAB isolates having the highest inhibitory effects were selected for biochemical identification using API 50 kit and these were identified as being; Lactobacillus plantarum (53\%), Lactobacillus rhamnosus (29\%), Pediococcus pentosaceus (6\%), Lactobacillus paracasei ssp. paracasei $(6 \%)$ and Lactococcus lactic ssp. lactis (6\%). Pediococcus pentosaceus showed the highest inhibitory effect on all the indicator strains. This study provides an insight into LAB diversity of unstudied Namibian fermented milk products and reports a potential production of antimicrobial compounds which is significant in the standardization of protective starter cultures which can be used to control fermentation process and shelf life extension of dairy products in Namibia.

\section{Keywords}

Namibia, Traditional Fermented Milk, Lactic Acid Bacteria, Omashikwa, Mabisi, Mashini ghamushikwa 


\section{Introduction}

Fermented Milk forms a major component of the traditional diet in many regions in Africa. Most of the milk produced is consumed in the house mostly by children and excess is infrequently sold in open markets to generate an income to the household. Due to limitation of cold storage facilities in many rural areas in African countries, milk is stored at ambient temperatures which usually allow them to become fermented rapidly by the natural flora. The fermentation process occurs spontaneously by back-sloping; i.e. inoculation of the raw material with a small quantity of the previously performed successful fermentation. Therefore, back-slopping results in dominance of the best adapted strains [1]. Modern techniques of milk fermentation, on the other hand, use starter cultures with known characteristics [2]. The advantage of modern techniques over the traditional methods is the production of consistent products that are less likely to spoil and are relatively safe.

Lactic acid bacteria (LAB) are widely distributed in nature, they are characterized as group of gram-positive, non-spore forming, cocci or rods, which produce lactic acid as the major end product during the fermentation of carbohydrates. The group consists of several genera, which include Enterococcus, Lactobacillus, Lactococcus, Leuconostoc, Pediococcus, and Streptococcus [3]. LABS are widely known to carry out safe metabolic activities in food and are mostly used for food preservation and flavor development [4]. Bio-preservation using lactic acid bacteria (LAB) and/or their antimicrobial metabolites are considered to be an alternative strategy for improving food safety [5]. As a result, there is an increased interest in the preservation through LAB because of their safe association with fermented foods. These antimicrobial properties of LAB are derived from competition for nutrients and the production of one or more antimicrobial active metabolites such as organic acids (mainly lactic and acetic acid), hydrogen peroxide and also other compounds, such as bacteriocins and antifungal peptides [5]. Specific attention has been given to bacteriocengenic LAB because it is believed that they provide an extra protection during the abuse of temperature conditions; decrease the risk for transmission of foodborne pathogens through the food chain; reduce chemical preservatives; reduce heat treatment without compromising food safety: better preservation of nutrients and vitamins, as well as sensorial properties of food [6]. In addition to that, they permit the marketing of "novel” food (less acidic, with a lower salt content and with a higher water content) to satisfy the demands of both the consumers and industry [5].

Earlier studies on Namibian fermented milk have concentrated on the sensory evaluation [7], technological properties [8] and microbiological [9] of Omashikwa. To our knowledge, little information exists on the traditional fermentative microflora that Omashikwa, Mabisi and Mashini Ghamushikwa use to produce these types of milk and their antimicrobial profile. The objective of this study was to isolate and identify the dominant LAB associated with Omashikwa, Mabisi, and Mashini Ghamushikwa, and to provide information on the potential production of antimicrobial compounds by these LAB for possible strain selection and development of starter culture for enhanced quality and safety of the three traditional fermented milk products.

\section{Materials and Methods}

\subsection{Sample Collection}

Thirteen (13) fermented milk samples of Omashikwa were collected from northern Namibia from the Oshana, Ohangwena, Omusati, and Oshikoto regions. The villages and households were randomly selected. Four (4) samples of Mabisi were collected from Zambezi region and three (3) Mashini Ghamushikwa from Kavango region. The samples were collected aseptically in sterile $250 \mathrm{ml}$ plastic bottles and kept in an ice-box and transported to the Food Biotechnology Laboratory at the Department of Chemistry and Biochemistry of the University of Namibia.

\subsection{Microbiological Analysis}

Samples (1 ml) of fermented milk were inoculated into $9 \mathrm{ml}$ of buffered peptone water (BPW). One ml of these aliquots was directly inoculated in triplicates on the following media: a) de Man Rogosa Sharp (MRS) agar incubated for 24 to 48 hours at $37^{\circ} \mathrm{C}$ for the isolation of Pediococcus and Streptococcus. b) M17 agar incubated aerobically at $30^{\circ} \mathrm{C}$ for 48 hours for enumeration of Lactococcus. c) Rogosa agar incubated for anaerobically at $35^{\circ} \mathrm{C}$ for 48 hours for the enumeration of Lactobacillus. Six colonies from MRS $\left(37^{\circ} \mathrm{C}\right) \mathrm{M} 17$ (30 $\left.{ }^{\circ} \mathrm{C}\right)$ and Rogosa agar $\left(35^{\circ} \mathrm{C}\right)$ representative of all the samples were randomly picked based on their colony morphology from different sections of plates containing 10 - 300 colony forming units (CFU) [10]. Isolates (180) were grown in 
MRS broth. The LAB isolates were purified by 4 consecutive sub-culturing in MRS agar and MRS broth (Oxoid) before identification. The isolates were gram stained and morphologically identified using a light microscope for the purity, cell shapes and arrangements. The isolates were transferred to MRS broth, incubated for 24 and were preserved in $25 \%$ of glycerol at $-80^{\circ} \mathrm{C}$ until further analysis [11].

\subsection{Antimicrobial Assay of LAB}

\subsubsection{Microorganisms and Culture Conditions}

Escherichia coli ATCC 25,922, Staphylococcus aureus ATCC 25,923, Bacillus cereus ATTC 10,876, Candida famata (IKST F. Lab. isolate) and Geotrichum klebahnii (IKST F. Lab. isolate) were used as test microorganisms or indicator strains. The indicator strains used for determination of inhibitory activity spectra of studied isolates were purchased from the American Type Culture Collection (ATCC) Stock cultures. Bacteria were kept in a refrigerator $\left(4^{\circ} \mathrm{C}\right)$ on nutrient agar slants. Geotrichum klebahnii was isolated from Namibian fermented food and beverages samples collected from/Karas region in the south of Namibia [12].

\subsubsection{Agar Well Diffusion Method}

Cell-free supernatants (CFS) for antibacterial assay was prepared by growing the LAB isolates in MRS broth at $37^{\circ} \mathrm{C}$ and centrifuged at $13,000 \times \mathrm{g}$ for $10 \mathrm{~min}$ at $4^{\circ} \mathrm{C}$ then $\mathrm{pH}$ was adjusted to 7 by $1 \mathrm{M} \mathrm{NaOH}$ to exclude the antimicrobial effect of organic acid [13]. The antimicrobial activity of the cell-free culture supernatants of isolated LAB against the indicator organisms was determined by the agar well diffusion method [13]. Aliquots of supernatants $(100 \mu \mathrm{L})$ were placed in wells (6 mm diameter) cut in cooled soft nutrient agar plates using a cock bore, previously seeded with $100 \mu \mathrm{L}$ of the appropriate indicator strains. The plates were first stored in the refrigerator for to allow LAB supernatant to set then incubated under optimal conditions for growth of the target microorganisms after which they were examined for clear zones around the wells. The diameters of the growth inhibition zones were measured and recorded in millimeter $(\mathrm{mm})$.

\subsection{Biochemical Identification of LAB}

The carbohydrate fermentation profiles of the selected $20 \mathrm{LAB}$ isolates were investigated using API $50 \mathrm{CH}$ strips and API CHL medium according to manufacturer's instruction (API system, BioMèrieux, France). Overnight cultures of the isolates grown in $10 \mathrm{ml}$ MRS broth at $30^{\circ} \mathrm{C}$ were washed twice with sterile peptone water and the pellets were re-suspended in API 50 CHL medium, using sterile pasture pipettes. With subsequent mixing, homogenized suspensions of the cells in the medium where transferred into each of the 50 wells on the API $50 \mathrm{CH}$ strips. Strips were covered as recommended and incubated at $30^{\circ} \mathrm{C}$. Changes in color were monitored after 24 hrs of incubation. Results were represented by positive sign (+) while a negative sign $(-)$ was designated for no change. The APIWeb ${ }^{\mathrm{TM}}$ V1.2.1. Software (BioMèrieux, France) was used according manufactures instruction in interpretation of the results.

\subsection{Statistical Analysis}

All the analysis was done in triplicates. Values of different tests were expressed as the mean \pm standard deviation $(x \pm S D)$. Statistical Package for Social Science (SPSS Inc., Chicago, IL) packet program for Windows (SPSS V. 12.0) was used for the statistical analysis. The different samples treatments were compared by performing one-way analysis of variance (ANOVA) on the replicates at 95\% level of significance.

\section{Results and Discussion}

\subsection{Identification of Lactic Acid Bacteria}

A total of 180 Gram-positive and catalase negative bacterial isolates were isolated from 20 samples of fermented milk products from north east Namibia. They were grouped and preliminary identified to the genus level based on their cell shape and arrangement (Table 1).

Out of the $180 \mathrm{LAB}$ isolates from the three types of fermented milk, most of the genera belonged Lactobacillus $88 \%$, Lactococcus 6\%, and Pediococcus 6\%. These results showed the heterogeneity in the three types of fermented milk Omashikwa, Mabisi and Mashini ghakushika from different regions or agro-climatic zones either in its chemical or microbial composition and quality attributes. 
Table 1. Morphological and biochemical characterization of bacteria isolates from Mabisi, Omashikwa and Mashini ghakushika that were collected from north-east in Namibia.

\begin{tabular}{|c|c|c|c|c|c|}
\hline \multirow[t]{2}{*}{ Genus } & \multicolumn{4}{|c|}{ Characteristics } & \multirow[t]{2}{*}{$\begin{array}{c}\text { Total number of } \\
\text { isolates } \\
\end{array}$} \\
\hline & Cell shape & Cellular arrangement & Catalase & Gram & \\
\hline Lactobacillus & Rods & Short rods, straight edges & - & + & 88 \\
\hline Lactobacillus & Rods & Long rods, rounded edges & - & + & 45 \\
\hline Streptococcus & Cocci & Chains, pairs & - & + & 27 \\
\hline Pediococcus & Cocci & $\begin{array}{l}\text { tetrads and pairs, } \\
\text { rounded edges }\end{array}$ & - & + & 20 \\
\hline
\end{tabular}

\subsection{Antimicrobial Activities of Lactic Acid Bacteria}

All the 180 isolates of LAB isolated from the three types of fermented milk were subjected to inhibitory activity test using well diffusion method (Figure 1). All LAB-CFS showed inhibition effect against Candida famata with an average of at least $6.08 \mathrm{~mm}$. In contrast, Bacillus cereus was the most resistant strain as only few CFS showed inhibition effects with an average of $1.07 \mathrm{~mm}$. The formation of small zones of inhibition using the well-diffusion-assay technique may be explained by the insufficient concentration of antimicrobial substances in the supernatant of the cultures [14] [15].

\subsection{Identification of the Inhibitory Substance(s) Producing LAB}

Twenty strains among 180 lactic acid bacteria isolated from the three types of milk “Omashikwa, Mashini ghakushika, and Mabisi” were selected according to their maximum antimicrobial activity against indicator strains. They were then identified from the production of acids from carbohydrates and related compounds using an API 50 CHL system (Biomérieux, France). Table 2 shows LAB species identified in five different species. The predominant species were Lactobacillus plantarum (9 strains), Lactobacillus rhamnosus (5 strains), Pediococcus pentosaceus 2 (1 strain), Lactococcus lactic ssp. lactis 1 (1 strains) and Lactobacillus paracasei ssp. paracasei 1 (1 strain).

Mabisi showed diversity of genera with four types of LAB species L. plantarum, L. paracasei ssp. paracasei, L. rhamnosus and Pediococcus pentosaceus. Omashikwa has only three species L. plantarum, L. rhamnosus and L. lactis ssp. lactis; these were in agreement with the reported study [9], when he found that the main dominant lactic acid bacteria belonged to Lactobacillus plantarum (25\%) and 15\% Lactococcus lactis ssp. lactis. The only difference was the Lactobacillus rhamnosus which was found in this study which was not the case with the reported study [9]. This may be attributed to high environmental temperatures during processing and probably the use of Boscia albitrunca (Omunkuzi) root. The dominance of Lactobacillus plantarum strains in Omashikwa and Mashini ghakushika could be associated with the root which is added during fermentation. Reference [16] stated that the presence of $L$. plantarum is known to be commonly associated with plant based food fermentations. Reference [17] reported that different strains of $L$. plantarum have been isolated from various niches, such as fermented milk, cheese, fermented cucumber, fermented olives, pasta, pineapple, grapefruit juice, sorghum beer and barley, molasses, boza, kefir and amasi. Lactobacillus plantarum can be considered as the most important and versatile species among LAB. It can adapt to various niches due to its ability to ferment a wide range of carbohydrates. Additionally, it can be used as starter culture in food fermentations and as an ingredient for probiotic foods, contributing to the organoleptic characteristics of foods at the same time prolonging the shelf-life and safety of these products [16]. Reference [18] emphasized that the preliminary identification of the inhibitory activity of LAB isolated from foods is essential for further studies about their antimicrobial activity. After antagonist activity is detected, complementary tests can be implemented to confirm the proteinaceous nature of the produced substances, to identify the spectrum of other sensitive microorganisms, to verify the factors that interfere with the antimicrobial activity and to verify the pathogenicity of the isolated cultures [14] [15] [19].

\section{Conclusion}

Microorganisms involved in Omashikwa, Mabasi and Mashini Ghakushika fermentation were found to consist of LAB from the three genera Lactobacillus, Lactococcus and Pediococcus. The dominant genus was Lactoba- 


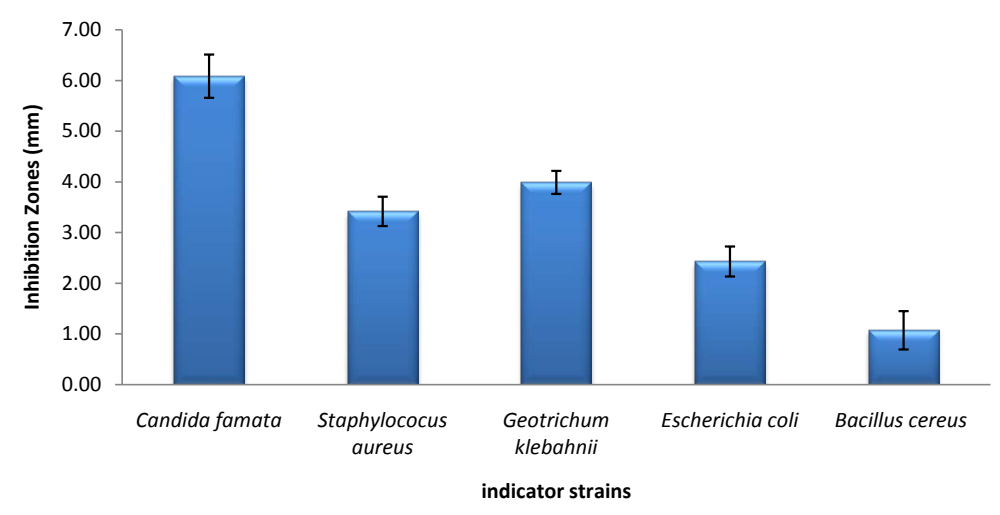

Figure 1. Average of Inhibition zones toward the indicator strains.

Table 2. Distribution of LAB species in omashikwa, mabisi and mashini ghakushika.

\begin{tabular}{cccc}
\hline \multirow{2}{*}{ LAB species } & \multicolumn{3}{c}{ Type of fermented milk } \\
\cline { 2 - 4 } & Omashikwa & Mabisi & Mashini ghakushika \\
\hline Lactobacillus rhamnosus & 5 & 1 & 2 \\
Lactococcus lactis ssp. lactis 1 & 1 & - & 1 \\
Lactobacillus plantarum 1 & 6 & 1 & - \\
Lactobacillus paracasei ssp. paracasei 1 & - & 1 & - \\
Pediococcus pentosaceus 2 & - & 1 & \\
\hline
\end{tabular}

cillus while the most dominant species were Lactobacillus plantarum, Lactobacillus rhamnosus, Pediococcus pentosaceus, Lactococcus lactic ssp. lactis and Lactobacillus paracasei ssp. Paracasei. Most inhibitory substances produced by lactic acid bacteria are safe and effective natural inhibitors of pathogenic and food spoilage bacteria in various foods. These microorganisms should be tested for their technological properties, microbial interactions and possible probiotic characterization. This will enable product development and innovation for prolonging the shelf-life and safety for dairy products in Namibia.

\section{Acknowledgements}

The authors would like to thank the Directorate of Research Science and Technology (DRST) of the Ministry of Education (Now called National Commission on Research Science and Technology (NCRST), the Research \& Publication office of the Pro-Vice Chancellor: Academic Affairs \& Research of the University of Namibia, and the Science, Technology and Innovation Division (ST\&ID) of Multidisciplinary Research Centre for their financial assistance.

\section{References}

[1] Steinkraus, K.H. (2002) Fermentations in World Food Processing. Comprehensive Reviews in Food Science and Food Safety, 1, 23-32. http://dx.doi.org/10.1111/j.1541-4337.2002.tb00004.x

[2] Chandan, R.C. and Shah, N.P. (2013) Functional Foods and Disease Prevention. In: Chandan, R.C. and Kilara, A., Eds., Manufacturing Yogurt and Fermented Milks, John Wiley \& Sons, Oxford, 411-431. http://dx.doi.org/10.1002/9781118481301.ch20

[3] Amenu, D. (2013) Antimicrobial Activity of Lactic Acid Bacteria Isolated from "Ergo", Ethiopian Traditional Fermented Milk. Current Research in Microbiology and Biotechnology, 1, 278-284.

[4] Khalid, K. (2011) An Overview of Lactic Acid Bacteria. International Journal of Biosciences, 1, 1-13.

[5] Reis, J.A., Paula, A.T., Casarotti, S.N. and Penna, A.L.B. (2012) Lactic Acid Bacteria Antimicrobial Compounds: Characteristics and Applications. Food Engineering Reviews, 4, 124-140. http://dx.doi.org/10.1007/s12393-012-9051-2 
[6] Robertson, A., Tirado, C., Lobstein, T., Jermini, M., Knai, C., Jensen, J.H., Ferro-Luzzi, A. and James, W.P.T. (2004) Food and Health in Europe: A New Basis for Action. European Series, WHO Regional Publications, Geneva.

[7] Bille, P.G., Ozuuko, A.T.R. and Ngwira, T. (2002) Sensory Properties of Traditionally Fermented Buttermilk (Omashikwa) Processed in Namibia. Journal of Food Technology in Africa, 7, 52-54. http://dx.doi.org/10.4314/jfta.v7i2.19244

[8] Bille, P.G., Buys, E. and Taylor, J.R.N. (2007) The Technology and Properties of Omashikwa, a Traditional Fermented Buttermilk Produced by Small-Holder Milk Producers in Namibia. International Journal of Food Science and Technology, 43, 620-624. http://dx.doi.org/10.1111/j.1365-2621.2006.01381.x

[9] Bille, P.G. (2013) Effect of Boscia albitrunca (Omukunzi) Root on the Bacteriology and Viscosity of Omashikwa, Traditional Fermented Buttermilk from Namibia. African Journal of Food, Agriculture, Nutrition and Development, 13, 7927-7943.

[10] Jans, C., Bugnard, J., Njage, P.M.K., Lacroix, C. and Meile, L. (2012) Lactic Acid Bacteria Diversity of African Raw and Fermented Camel Milk Products Reveals a Highly Competitive, Potentially Health-Threatening Predominant Microflora. LWT-Food Science and Technology, 47, 371-379. http://dx.doi.org/10.1016/j.lwt.2012.01.034

[11] Li, W., Mutuvulla, M., Chen, X.H., Jiang, M. and Dong, M. (2012) Isolation and Identification of High Viscosity-Producing Lactic Acid Bacteria from a Traditional Fermented Milk in Xinjiang and Its Role in Fermentation Process. European Food Research and Technology, 235, 497-505. http://dx.doi.org/10.1007/s00217-012-1779-7

[12] Cheikhyoussef, A. (2011) Pilot Study on the Indigenous Knowledge Systems on Foods and Beverages in Selected Areas in Karas Region, Namibia. University of Namibia, Windhoek.

[13] Cheikhyoussef, A., Pogori, N., Chen, H.Q., Tian, F.W., Chen, W., Tang, J. and Zhang, H. (2009) Antimicrobial Activity and Partial Characterization of Bacteriocin-Like Inhibitory Substances (BLIS) Produced by Bifidobacterium infantis BCRC 14602. Food Control, 20, 553-559. http://dx.doi.org/10.1016/j.foodcont.2008.08.003

[14] Harris, L.J., Daeschel, M.A., Stiles, M.E. and Klaenhammer, T.R. (1989) Antimicrobial Activity of Lactic Acid Bacteria against Listeria monocytogenes. Journal of Food Protection, 52, 384-387.

[15] Lewus, C.B. and Montville, T.J. (1991) Detection of Bacteriocins Produced by Lactic Acid Bacteria. Journal of Microbiological Methods, 13, 145-150. http://dx.doi.org/10.1016/0167-7012(91)90014-H

[16] da Silva Sabo, S., Vitolo, M., González, J.M.D. and de Souza Oliveira, R.P. (2014) Overview of Lactobacillus plantarum as a Promising Bacteriocin Producer among Lactic Acid Bacteria. Food Research International, 64, 527-536. http://dx.doi.org/10.1016/j.foodres.2014.07.041

[17] Todorov, S.D., LeBlanc, J.G. and Franco, B.D.G.M. (2012) Evaluation of the Probiotic Potential and Effect of Encapsulation on Survival for Lactobacillus plantarum ST16Pa Isolated from Papaya. World Journal of Microbiology and Biotechnology, 28, 973-984. http://dx.doi.org/10.1007/s11274-011-0895-z

[18] Moraes, P.M., Perin, L.M., Ortolani, M.B.T., Yamazi, A.K., Viçosa, G.N. and Nero, L.A. (2010) Protocols for the Isolation and Detection of Lactic Acid Bacteria with Bacteriocinogenic Potential. LWT-Food Science and Technology, 43, 1320-1324. http://dx.doi.org/10.1016/j.lwt.2010.05.005

[19] Rodriguez, E., Gonzalez, B., Gaya, P., Nunez, M. and Medina, M. (2000) Diversity of Bacteriocins Produced by Lactic Acid Bacteria Isolated from Raw Milk. International Dairy Journal, 10, 7-15.

http://dx.doi.org/10.1016/S0958-6946(00)00017-0 